\title{
ESTUDO DA ADSORÇÃO DO CORANTE AZUL DE METILENO UTILIZANDO A CASCA DO TAMARINDOCOMO BIOSSORVENTE
}

\author{
J. A. D. BARROSO ${ }^{1}$, L. R. LOPES$^{1}$ e R. N. da CUNHA ${ }^{1}$ \\ ${ }^{1}$ Centro Universitário de Patos de Minas, Departamento de Engenharia Química \\ E-mail para contato: junia.engenhariaquimica@gmail.com
}

\begin{abstract}
RESUMO- A adsorção é muito utilizada no tratamento de águas contaminadas por corantes orgânicos devido à sua elevada eficiência e baixo custo operacional. $\mathrm{O}$ estudo de adsorventes alternativos fornece subsídios científicos para o reaproveitamento tecnológico de resíduos em operações industriais. Este estudo visou a análise do potencial adsorvente, da casca do tamarindo, sobre o corante azul de metileno, avaliando-se as curvas de cinética de adsorção. Em coluna de leito fixo, foram estimados os efeitos dos parâmetros: pH e concentração de adsorvato; tamanho de partícula biossorvente e altura de leito estático. A partir dos resultados, observou-se que a casca do tamarindo tem potencial adsorvente e que as condições ótimas de operação são: pH básico (10), elevadas concentrações da solução (50 $\mathrm{mg} / \mathrm{L}$ ) e partículas menores de adsorvente (48 mesh). Para a modelagem cinética, os modelos que se ajustaram para a adsorção foram o de pseudo-primeira ordem e pseudo-segunda ordem, mostrando que o processo baseia-se na capacidade de adsorção do sólido.
\end{abstract}

\section{INTRODUÇÃO}

Entre os problemas enfrentados pela indústria têxtil na atualidade, destaca-se a remoção de corantes orgânicos do efluente gerado pelo processo produtivo. Tais poluentes são extremamente nocivos ao ecossistema e à saúde da população em geral. Mais de 700 mil toneladas de 10 mil tipos de corantes e pigmentos são produzidos anualmente no mundo, sendo o Brasil responsável por 2,6\% dessa demanda (Zanoni et al., 2001).

A indústria têxtil é uma das indústrias responsáveis pela geração de efluentes ricos em corantes. Estes corantes são tóxicos e causam a bioacumulação da cadeira trófica e, por esta razão, conselhos ambientais exigem que os efluentes gerados por estas indústrias atendam a critérios mínimos para o despejo em corpos d'água (Silva, 2011).

Segundo Gonsalves (2014), a adsorção tem se destacado do ponto de vista operacional e econômico dada à simplicidade de execução e ao baixo custo de implementação e manutenção pelas indústrias, na remoção de corantes orgânicos. Adsorventes alternativos como cascas de materiais orgânicos vêm sendo adotados com êxito neste setor uma vez que confere aplicabilidade a materiais, muitas vezes considerados resíduos bem como reduz custos no tratamento de águas poluídas. Dentre os biossorventes utilizados em outros estudos, cita-se, como exemplo, resíduos da casca de arroz (Mimura, 2010) e da casca de banana (Rabelo, 2009). 
O Tamarindo (Tamarindus indica) é uma vargem alongada com casca quebradiça,insolúvel em água e de aspecto lenhoso, cujo tamanho varia entre 5 e $15 \mathrm{~cm}$. A casca do tamarindo é considerada um resíduo sem reaproveitamento tecnológico (Gonsalves, 2014), porém com um grande potencial para estudos, pois possuir aspecto poroso, delgado e frágil, características que tornam esse material um potencial adsorvente.

A presente pesquisa tem como objetivo avaliar o potencial adsorvente da casca de tamarindo, provinda de resíduos de uma indústria de despolpamento, sobre o adsorvato azul de metileno, um dos corantes utilizados na indústria têxtil. São, ainda, objetos de escopo desta pesquisa: estudar a cinética de adsorção e estimar os efeitos do $\mathrm{pH}$, da granulometria do biossorvente e da concentração do adsorvato sobre a adsorção do corante azul de metileno.

\section{MATERIAISE MÉTODOS}

\subsection{O Biomaterial}

Os resíduos de tamarindo utilizados como biossorventes foram coletados em uma empresa destinada ao processamento de polpa de frutas, situada na região do Triângulo Mineiro. O beneficiamento do resíduo se fez por meio da retirada das sementes e fibras residuais. Realizou-se a secagem em estufa à temperatura de $90^{\circ} \mathrm{C}$ com recirculação de ar até peso constante. $\mathrm{O}$ material seco foi triturado com o auxílio de um liquidificador industrial marca Metvisa, e em seguida peneirado. Foram adotados como objeto de estudo as cascas retidas nas peneiras de 16,32 e 48 mesh.

\subsection{O Corante e a Curva de Calibração}

As soluções aquosas de corante azul de metileno foram preparadas previamente nas concentrações de 30 e50 mg/L. A construção da curva de calibração foi realizada em colorímetro CL 3003 Photomater por meio da leitura da absorbância no comprimento de onda de $660 \mathrm{~nm}$.O ajuste do $\mathrm{pH}$ foi realizado por meio da adição de soluções de $\mathrm{HCl}$ e $\mathrm{NaOH}$ a 0,1 mol. $L^{-1}$

\subsection{Ensaios de Adsorção na Coluna}

Os ensaios de cinética de adsorção foram realizados em coluna de vidro de $7 \mathrm{~cm}$ de diâmetro. O sistema é composto por válvulas, tanques de armazenamento, coluna de adsorção, bomba, manômetros, painel de controle e rotâmetro. A adsorção em coluna se fez pela passagem do fluido pelo leito fixo, sendo adotadas vazões constantes de $50 \mathrm{mg} . \mathrm{L}^{-1}$. A amostragem foi realizada em intervalo de tempo fixo, após a passagem pela coluna de adsorção, medindo-se a absorbância das alíquotas, a fim de se obter o ponto de saturação. Dentro desse contexto, foram avaliados os efeitos do $\mathrm{pH}$, da granulometria, da concentração sobre a adsorção do corante cujas parametrizações são apresentadas na Tabela 1.Com os resultados obtidos foram construídas as curvas de ponto de ruptura, ou seja, razão entre a concentração do cátion removido e a concentração inicial do corante $\left(C / C_{0}\right)$ em função do tempo. Segundo Alves (2013), o breaktrough, ou ponto de ruptura é atingido quando a parte da zona de adsorção atinge o fundo do leito, tornando a concentração do contaminante com um valor apreciável. As quantidades de corantes adsorvidos no processo de biossorção $\left(Q_{t}\right)$ foram calculadas utilizando-se a Equação 01. 
Tabela 1- Parâmetros adotados nos ensaios de adsorção

\begin{tabular}{|c|c|c|c|c|}
\hline Ensaios & $\mathbf{p H}$ & $\begin{array}{c}\text { Concentração } \\
{\left[\mathbf{m g . L}^{-1} \text { ] }\right.}\end{array}$ & $\begin{array}{c}\text { Granulometria } \\
{[\mathbf{m e s h}]}\end{array}$ & $\begin{array}{c}\text { Altura do leito } \\
\text { estático [cm] }\end{array}$ \\
\hline \hline 1 & 3,5 & 30 & 16 & 5 \\
\hline 2 & 3,5 & 30 & 48 & 5 \\
\hline 3 & 10,5 & 50 & 16 & 2 \\
\hline 4 & 3,5 & 30 & 16 & 2 \\
\hline 5 & 10,5 & 30 & 16 & 2 \\
\hline
\end{tabular}

$Q_{t}=\frac{C_{0} Q}{1000} \times \int_{0}^{t}\left(1-\frac{C}{C_{0}}\right) d t$

em que: $\mathrm{Q}_{\mathrm{t}}$ é a quantidade de corante adsorvido[mg. $\left.\mathrm{g}^{-1}\right] ; \mathrm{C}_{0}$ é a concentração inicial de corante[mg. $\mathrm{L}^{-}$ ${ }^{1}$ ]; C é a concentração de corante [mg. $\left.\mathrm{L}^{-1}\right]$; t é o tempo [min]; $Q$ : vazão volumétrica[mL.min $\left.{ }^{-1}\right]$.

No estudo do potencial de capacidade de adsorção do corante azul de metileno pela casca de tamarindo, obtiveram-se as curvas de ruptura avaliando-se a influência dos parâmetros: granulometria do biossorvente, $\mathrm{pH}$ e concentração do corante na solução de alimentação do leito e altura de leito estático.Os dados de cinética possuem elevada relevância no scale-up de sistemas de biossorção bem como corroboram na definição dos mecanismos envolvidos nos processos de adsorção, sendo assim, foram avaliados os modelos apresentados na Tabela 2.

Tabela 2- Modelos de cinética de adsorção ajustados aos dados experimentais

\begin{tabular}{|c|c|l|}
\hline Modelos & \multicolumn{1}{|c|}{ Equações } & \multicolumn{1}{|c|}{ Características } \\
\hline \hline $\begin{array}{c}\text { Pseudo-primeira } \\
\text { ordem }\end{array}$ & $Q_{t}=Q_{e}\left(1-e^{t K_{1}}\right)(02)$ & $\begin{array}{l}\text { Adsorção pela ocupação de um } \\
\text { sítio ativo do adsorvente. }\end{array}$ \\
\hline $\begin{array}{c}\text { Pseudo-segunda } \\
\text { ordem }\end{array}$ & $Q_{\mathrm{t}}=\frac{\mathrm{Q}_{\mathrm{e}}^{2} \cdot \mathrm{k}_{2} \cdot \mathrm{t}}{\left(1-\mathrm{Q}_{\mathrm{e}} \cdot \mathrm{k}_{2} \cdot \mathrm{t}\right)}(03)$ & $\begin{array}{l}\text { Adsorbato ocupa adsorvente por } \\
\text { dois sítios ativos. }\end{array}$ \\
\hline $\begin{array}{c}\text { Difusão } \\
\text { Intraparticula }\end{array}$ & $Q_{d i f} \cdot t^{\frac{1}{2}}(04)$ & $\begin{array}{l}\text { Adsorbato passa pelos poros do } \\
\text { adsorvente. }\end{array}$ \\
\hline Elovich & $\ln (\alpha \beta)+\frac{1}{\beta} \cdot \ln (t)(05)$ & $\begin{array}{l}\text { Determinação da cinética de de } \\
\text { quimissorção de gases em suportes } \\
\text { sólidos heterogêneos. }\end{array}$ \\
\hline
\end{tabular}

em que, $Q_{t}$ e $Q_{e}$ são as quantidades de adsorvato retidas por grama do adsorvente no tempo e no equilíbrio, respectivamente $\left[\mathrm{mg}_{\mathrm{g}} \mathrm{g}^{-1}\right] ; \mathrm{K}_{1}$ é a constante cinética $\left[\mathrm{min}^{-1}\right]$; $\mathrm{t}$ é o tempo em minutos; $\mathrm{K}_{2}$ constante cinética $\left[\mathrm{g} /\left(\mathrm{mg} \cdot \mathrm{min}^{-1}\right)\right] ; \mathrm{K}_{\mathrm{dif}}$ é a constante cinética $\left[\mathrm{mol} \cdot \mathrm{g}^{-1} \cdot \mathrm{min}^{-1 / 2}\right] ; \alpha$ é a taxa inicial de velocidade de adsorção $\left[\mathrm{mg}_{\mathrm{g}} \mathrm{g}^{-1} \mathrm{~min}^{-1}\right]$ e $\beta$ indica a extensão da cobertura da superfície de energia de ativação para a adsorção $\left[\mathrm{g} \cdot \mathrm{mg}^{-1}\right]$.

\section{RESULTADOS E DISCUSSÕES}

\subsection{Efeitos dos parâmetros de estudo}

A Figura 1(A) mostra a curva de ruptura, para um leito constituído de partículas retidas nas peneiras de 16 e 48mesh, mantidos constantes (concentração de corante de $30 \mathrm{mg} . \mathrm{L}^{-1}$; pH de 3,5; altura de leito estático de $5 \mathrm{~cm}$ ). Nota-se que granulometrias menores (48 mesh) promoveram maiores retenções do corante, ou seja, possuem maior capacidade de adsorção. $\mathrm{O}$ resultado obtido se deve ao aumento da superfície de contato, que contribui para adsorção, 
pois a saturação ocorre de forma mais lenta (Curbelo, 2002). Resultados similares foram obtidos por Menezes (2010) em sua pesquisa sobre a remoção do corante azul reativo 5G utilizando o bagaço do maracujá amarelo em sistema batelada.A Figura 1(B) mostra as curvas de ruptura, para leitos estáticos de 2 e $5 \mathrm{~cm}$ (concentração de corante de $30 \mathrm{mg} . \mathrm{L}^{-1}$; pH de 3,5; granulometria de 16 mesh). Conforme esperado, o aumento da altura do leitoresultou no aumento da eficiência de remoção devido à maior quantidade de adsorvente que confere maior quantidade de sítios ativos disponíveis e maior capacidade de adsorção pelo leito.

Figura 1 - Efeito da granulometriade partícula (A) e da altura de leito estático (B) sobre à adsorção de azul de metileno
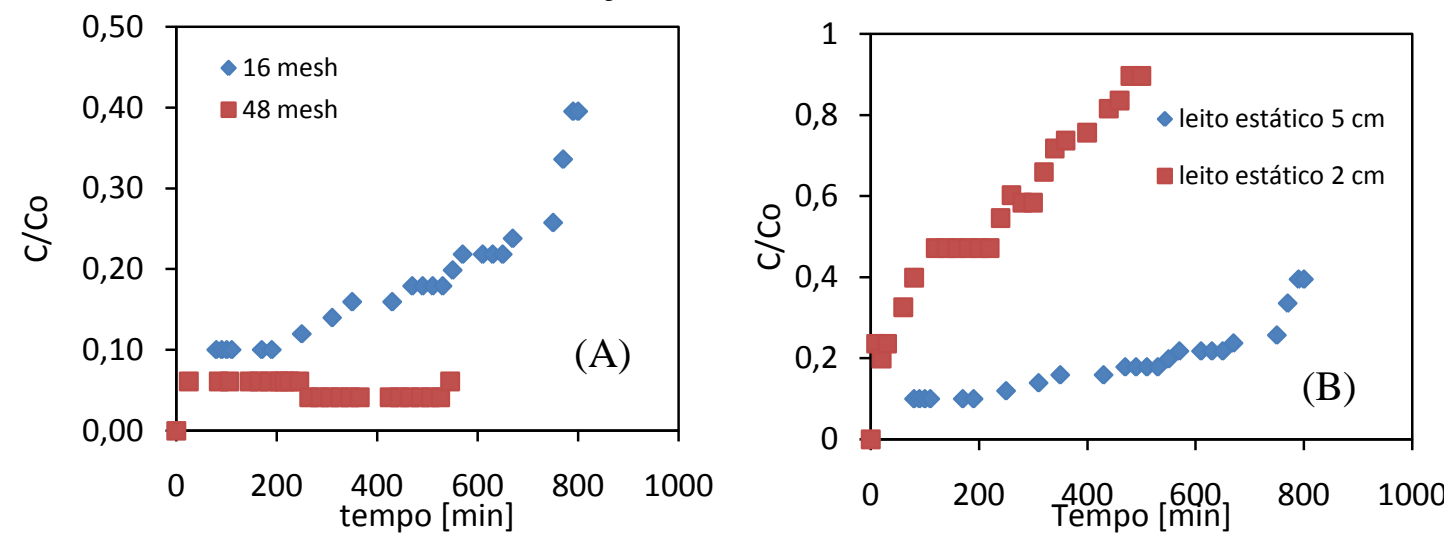

A Figura 2(A) mostra as curvas de ruptura obtidas em experimentos dois diferentes $\mathrm{pHs}$ mantidas as demais condições constantes (concentração de corante de $30 \mathrm{mg} . \mathrm{L}^{-1}$; altura de leito de $7 \mathrm{~cm}$; granulometria de $16 \mathrm{mesh}$ ). Verifica-se que o $\mathrm{pH}$ alcalino favoreceu a remoção do corante. Este fato pode ser explicado pela dissociação de grupos funcionais presentes nos sítios ativos do adsorvente (Mallet al., 2006) e pelo caráter catiônico da molécula de azul de metileno. Em pH=3,5 pode ocorrer a competição entre os íons $\mathrm{H}+$ em solução e essas moléculas diminuindo a eficiência de adsorção nesse pH (Leal et al., 2012). O efeito da concentração da solução de corante é evidenciado na Figura 2 (B) no pH de 10,5; altura de leito estático de $2 \mathrm{~cm}$ e granulometria de $16 \mathrm{mesh}$ ).

Figura 2 -Efeito do $\mathrm{pH}$ (A) e da concentração de azul de metileno(B) sobre a adsorção
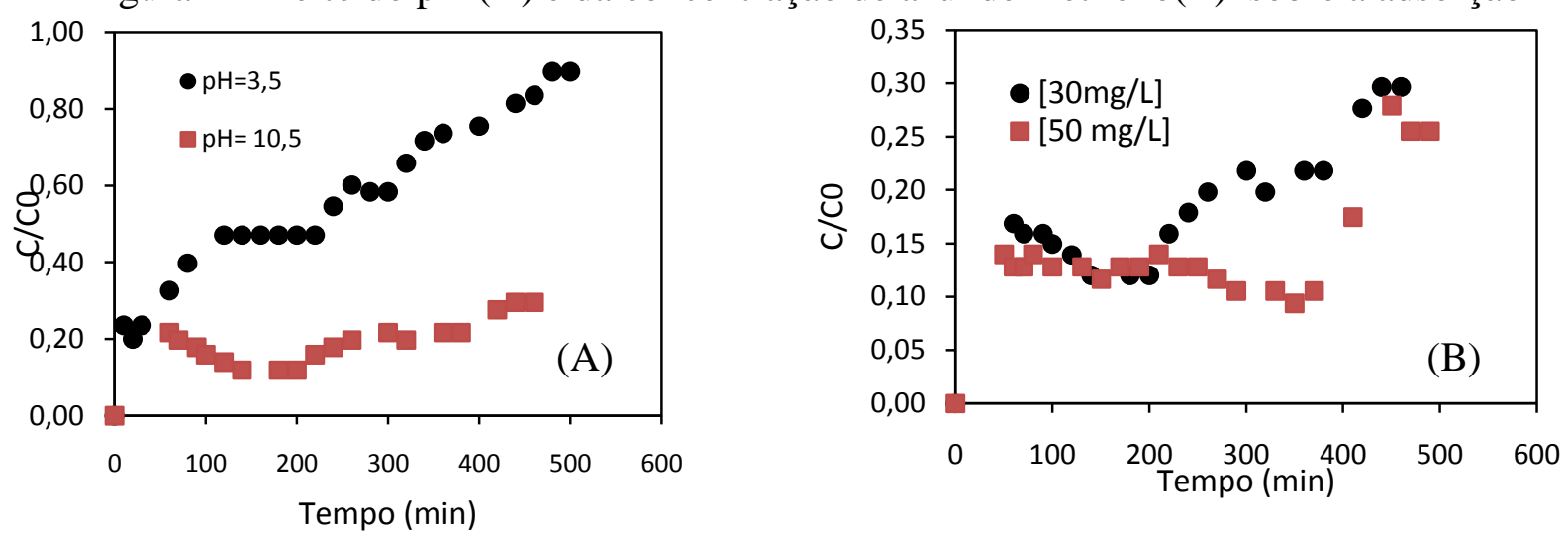

Os resultados evidenciam que em baixas concentrações, o leito satura-se desigualmente em maior proporção. Ao aumentar a concentração inicial de azul de metileno, há mais 
espécies distribuídas na superfície do adsorvente, o que contribui para uma maior formação de ligações químicas na superfície (Leal et al., 2012).

\section{2 Modelos cinéticos de adsorção}

O mecanismo controlador da adsorção foi investigado pelo ajuste de diversos modelos cinéticos, cujos resultados são apresentados na Figura 3 e Tabela 3. Ressalta-se que o ajuste aos modelos foi realizado apenas para o ensaio experimental 4 , no qual foi possível obter o ponto de saturação $\left(\mathrm{C} / \mathrm{C}_{0}\right.$ próximo de 1$)$.

Figura 3-Quantidade de adsorvato por massa de adsorvente em função do tempo, com equações ajustadas aos dados experimentais

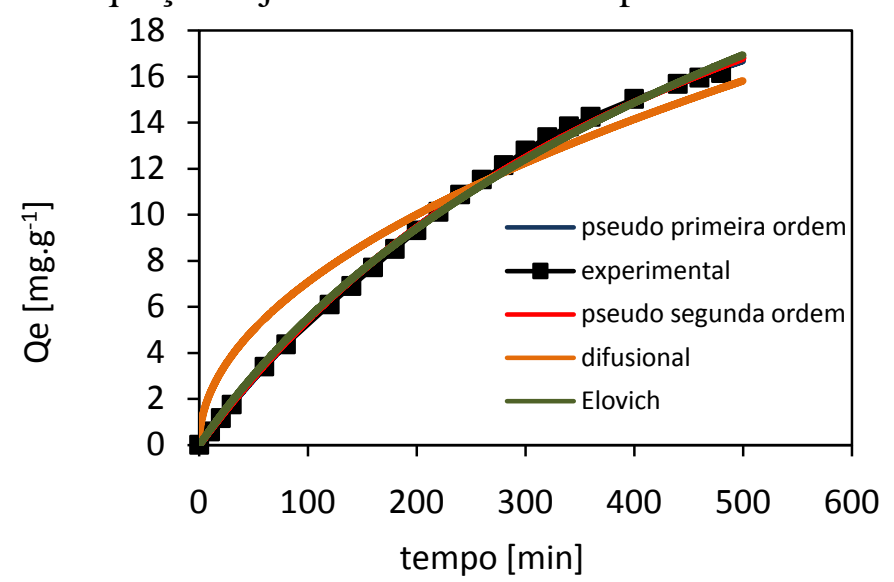

Avaliando-se as magnitudes dos coeficientes de correlação da curva $\left(\mathrm{R}^{2}\right)$, nota-se que os modelos de pseudo-primeira e pseudo-segunda ordem são os mais indicados na predição da cinética de adsorção. Resultados similares foram obtidos por Bonetto (2016), em estudo de adsorção do corante azul de metileno em resíduo de suco de maçã. Yagub et al. (2014) citado por Bonetto (2016), acrescenta que o modelo de pseudo-segunda ordem apresenta bom ajuste à adsorção envolvendo corantes, pautando-se na contribuição das características físicoquímicas do biossorvente (Tabela 3).

Tabela 3 - Parâmetros cinéticos obtidos para os modelos avaliados.

\begin{tabular}{|c|c|c|c|}
\hline Descrição & \multicolumn{2}{|c|}{ Constantes } & $\mathrm{R}^{2}$ \\
\hline Pseudo-primeira ordem & $\mathrm{K}_{1\left(\mathrm{~min}^{-1}\right)}$ & 0,00643 & 0,9989 \\
\hline Pseudo-segunda ordem & $\mathrm{K}_{2}\left(\mathrm{~g}, \mathrm{mg}^{-1} \cdot \mathrm{min}^{-1}\right)$ & 0,00005 & 0,9982 \\
\hline Difusão intrapartícula & $\mathrm{K}_{\mathrm{dif}}\left(\mathrm{g}, \mathrm{mg}^{-1} \cdot \mathrm{min}^{-1 / 2}\right)$ & 0,70732 & 0,9514 \\
\hline \multirow[t]{2}{*}{ Elovich } & $\alpha\left(\mathrm{mg}, \mathrm{g}^{-1} \mathrm{~min}^{-1}\right)$ & 0,06828 & \multirow[t]{2}{*}{0,9973} \\
\hline & $\beta\left(\mathrm{g}, \mathrm{mg}^{-1 .}\right)$ & 0,07489 & \\
\hline
\end{tabular}

\section{CONSIDERAÇÕES FINAIS}

A partir dos resultados obtidos foi possível observar a eficácia da casca de tamarindo como biossorvente na adsorção do corante azul de metileno, onde as condições ótimas de operação, dentre as testadas, foram: pH básico $(10,5)$,elevadas concentrações da solução de azul de metileno $(50 \mathrm{mg} / \mathrm{L})$ e partículas menores de adsorvente (48 mesh). Para a modelagem cinética, obtida por meio de regressão não linear, os modelos que se ajustaram aos dados 


\section{Congresso Brasileiro de Engenharia Química \\ em Iniciação Científica \\ UFSCar - São Carlos - SP \\ 16 a 19 de Julho de 2017}

experimentais foram o de pseudo-primeira ordem e pseudo-segunda ordem, mostrando que o processo baseia-se na capacidade de adsorção do sólido. Os resultados obtidos na adsorção de solução de azul de metileno em resíduos de tamarindo mostram o potencial promissor do uso desse material como adsorvente.

\section{REFERÊNCIAS}

ALMEIDA R. R. G., et al., Módulo MultipropósitoUpcontrol no Ensino de Operações Unitárias: Coluna de Adsorção. Encontro Brasileiro sobre Adsorção, 10., 2014, Guarujá-SP 2014. 6 p.

ALVES, Fernanda Cristina. Estudo dos processos de adsorção utilizando argilas como adsorventes para remoção do corante verde m. 2013. 107 f. Dissertação (Mestrado) - Curso de Agroquímica, Universidade Federal de Lavras, Lavras, 2013

BONETTO, Luis Rafael. Estudo da adsorção do corante azul de metileno por um resíduo sólido da indústria de suco de maçã. 2016. 151 f. Dissertação (Mestrado) - Curso de Engenharia e Ciência dos Materiais, Universidade de Caxias do Sul, Caxias do Sul, 2016.

CURBELO, F. D. da S.; OLIVEIRA, E. L. de; Estudo da remoção de óleo em águas produzidas na indústria de petróleo, por adsorção em coluna utilizando a vermiculita expandida $e$ hidrofobizada. 2002. 102 f. Dissertação (Mestrado) - Curso de Engenharia Química, Departamento de Engenharia QuÍmica, Universidade Federal do Rio Grande do Norte, Natal- Rn, 2002.

GONSAlVES, A. A.;LEITE FILHO, C. A.; MEdeIROS, F. S.; ARAÚJO, C. R. M.Casca do tamarindo: caracterização e estudos de adsorção de azul de metileno e cromo(vi) usando a técnica de banho finito de líquido. Petrolina- Pe: Revista Virtual de Química, v. 6, n. 5, 05 jun. 2014

LEAL, Paulo Vitor Brandão et al. Estudo da adsorção do corante azul de metileno em resíduos de babaçu. Journal Of Biotechnology And Biodiversity. p. 166-171. nov. 2012.

MALL, I. D.; SRIVASTAVA, V. C.; AGARWAL, N. K. 2006.Removal of Orange-G and Methyl Violet dyes by adsorption onto bagasse fly ash - kinetic study and equilibrium isotherm analyses. DyesandPigments.Vol69, p. 210-223.

MENEZES, Maraíza Lopes de. Remoção do Corante Reativo Azul $5 g$ a partir de Soluções Aquosas Utilizando o Bagaço do Maracujá Amarelo como Adsorvente. 2010. 139 f. Dissertação (Mestrado) Curso de Engenharia Química, Departamento de Engenharia QuÍmica, Universidade Estadual de Maringá, Maringá- Pr, 2010. Cap. 21.

Mimura, A. M. S.; Vieira, T. V. de A.; Martelli, P. B.; Gorgulho, H. de F. Aplicação da casca de arroz na adsorção dos íons Cu2+, Al3+, Ni2+ e Zn2+. Química Nova2010, 33, 1279.

RABELO, R. B.; ALBARELlI, J. Q.; Resumos do VI Encontro Nacional de Engenharia e Desenvolvimento Social, Campinas, Brasil, 2009.

SILVA JUNIOR, Robson Pinheiro da; SILVA1, Georgtown Almir Oliveira da; ARAÚJO, Cleônia Roberta Melo. Uso da casca de tamarindo (Tamarindus indica l.) Em estudos de adsorção de safranina usando a técnica de coluna. 2014. Dissertação (Mestrado) - Curso de Engenharia Química, Universidade Federal do Vale do São Francisco, Vale do São Francisco, 2014.

ZANONI , M. V. B. \& CARNEIRO, P A. O descarte dos corantes têxteis. Ciência Hoje. v.29, n. 174, p. 62-63, 200. 